\section{FACTORES EPISTEMOLÓGICOS Y CONTEXTUALES EN LA GENEALOGÍA DE LA TEORÍA DE LA FOTOGRAFÍA EN LA SEGUNDA MITAD DEL SIGLO XX}

\author{
Enric Mira Pastor \\ Universidad de Alicante \\ ORCID iD: https://orcid.org/0000-0001-6110-1719
}

enric.mira@ua.es

Cómo citar este artículo/Citation: Mira Pastor, Enric (2020). Factores epistemológicos y contextuales en la genealogía de la teoría de la fotografía en la segunda mitad del siglo XX. Arbor, 196 (798): a584. https://doi.org/10.3989/arbor.2020.798n4008

Recibido: 4 febrero 2020. Aceptado: 21 mayo 2020.

RESUMEN: El giro crítico del arte conceptual en los años sesenta, la subsiguiente aparición de estrategias de hibridación y escenificación a finales de los setenta y, en paralelo, la institucionalización de la fotografía con su entrada al museo y el surgimiento de un pujante mercado fotográfico, constituyen el caldo de cultivo en el que se gesta la demanda de la teoría de la fotografía como disciplina con identidad epistemológica propia. Esta demanda se hizo explícita a través de las iniciativas llevadas a cabo por Rosalind Krauss y Annette Michelson en el número 5 de la revista October en 1978, por Alan Trachtenberg en Classic Essays on Photography en 1980 y de modo más categórico por Victor Burgin en Thinking Photography en 1982. El presente artículo analiza los argumentos y posiciones intelectuales sobre la necesidad de articular un discurso teórico sobre fotografía, así como los aspectos epistemológicos y sociales asociados a la idea de teoría subyacente en cada una de las propuestas. Por último, se realiza una breve aproximación al ámbito teórico español a través de la publicación en 1984 del libro Estética fotográfica y en 1997 de El beso de Judas, ambos de Joan Fontcuberta.

PALABRAS CLAVE: Teoría de la fotografía; estética de la fotografía; arte conceptual; identidad epistemológica; interdisciplinariedad.

\section{EPISTEMOLOGICAL AND CONTEXTUAL FACTORS IN THE GENEALOGY OF PHOTOGRAPHY THEORY IN THE SECOND HALF OF THE 20TH CENTURY}

Copyright: (C) 2020 CSIC. Este es un artículo de acceso abierto distribuido bajo los términos de la licencia de uso y distribución Creative Commons Reconocimiento 4.0 Internacional (CC BY 4.0).

ABSTRACT: The critical shift of conceptual art in the 1960s, the subsequent appearance of hybridization and staging strategies in the late 1970s and, at the same time, the institutionalization of photography with its entrance into the museum and the emergence of a thriving photographic market, constitute the breeding ground in which the demand for photography theory as a discipline with its own epistemological identity began to take shape. This demand was made explicitly through initiatives done by Rosalind Krauss and Annette Michelson in special issue $n^{\circ} 5$ of the October academic journal in 1978, by Alan Trachtenberg in the volume Classic Essays on Photography in 1980 and more categorically by Victor Burgin in his book Thinking Photography in 1982. This paper analyses the intellectual arguments and positions on the need to articulate a theoretical discourse on photography, as well as the epistemological and social aspects associated with the idea of theory underlying each of the proposals. Finally, a brief approach to the Spanish theoretical field is done through the publication in 1984 of the book Estética fotográfica and in 1997 of El beso de Judas, both by Joan Fontcuberta.

KEYWORDS: Photography theory; aesthetics of photography; conceptual art; epistemological identity; interdisciplinarity. 


\section{INTRODUCCIÓN}

A comienzos de este siglo Michael Fried (2008) se preguntaba por qué la fotografía había llegado a importar como arte como nunca antes. No era una pregunta retórica sino la constatación del papel central de la fotografía -al menos de cierta fotografíadentro de las prácticas artísticas contemporáneas. El fenómeno necesitaba de análisis y el crítico norteamericano lo abordaba desde premisas inspiradas en el formalismo modernista. De manera análoga, partiendo del hecho de que en el momento actual la fotografía despierta un inusitado interés teórico, cabría interrogarse por qué el pensamiento y la reflexión en torno a la fotografía adquiere esta importancia desconocida hasta el momento, y preguntarse también por los factores que lo desencadenaron. Ambos fenómenos están estrechamente relacionados y, como más adelante comprobaremos, el protagonismo adquirido por la fotografía como arte -su presencia paralela en museos y galerías- es inseparable de la atención prestada al medio fotográfico desde un punto de vista crítico y especulativo. Círculos académicos y centros de educación artística además de críticos, comisarios y practicantes del medio fotográfico serán parte de un proceso de institucionalización teórica que, como observa el historiador François Brunet (2000: 15), ha operado a modo de des-vulgarización de la fotografía que recalifica su rol en la cultura y en la sociedad contemporáneas. Aquella fotografía que Pierre Bourdieu (2003) definió como un "arte medio», a mitad de camino entre el arte elevado y la cultura popular, carente de legitimación estética y de discurso teórico, se verá transformada en práctica cultivada a partir de ahora.

La perspectiva socio-histórica que consolidaba el estudio La fotografía como documento social (2001) de Gisèle Freund, publicado en 1974, la visión de crítica cultural de Susan Sontag (2007) plasmada en Sobre la fotografía en 1977 o el influyente ensayo La cámara lúcida de Roland Barthes (1990) que, en 1980, configuraba una nueva aproximación a la fotografía con los conceptos de studium y punctum -tan alejados de sus anteriores análisis semiológicos de la imagen (Barthes, 1996)-, abonaron la creación de un fecundo "territorio teórico» sobre "lo fotográfico» (Dubois, 2016: 3) o, por decirlo en palabras de Rosalind Krauss (2002: 14), convirtieron a la fotografía en "objeto teórico", un territorio cuya orografía temática continúa siendo motivo de reflexión y objeto de discusión para los pensadores contemporáneos de la fotografía (Wells, 2004; Elkins, 2007; Batchen, 2009;
Costello, 2018) ${ }^{1}$. En los últimos tiempos, la diversa y ubicua fenomenología de lo fotográfico, en profunda transformación por las innovaciones de la tecnología digital (Mitchell, 1992; Iglhaut et al., 1996; Lister et al., 2003) y la nueva economía de lo visual surgida con la web 2.0 (Rubinstein y Sluis, 2008; Fontcuberta, 2010; Van House, 2011; Gómez-Cruz, 2012; Martín Prada, 2018) no han hecho sino ahondar en la necesidad de (re)pensar la fotografía en sus dimensiones social, epistémica y estética.

\section{DE LA PRÁCTICA A LA TEORÍA Y VICEVERSA}

La reflexión en torno al medio fotográfico es tan antigua como la misma fotografía. Los fotógrafos siempre han hablado y escrito en relación a su práctica. Durante el siglo XIX y las primeras décadas del XX lo hacían principalmente sobre cuestiones como la condición artística de la fotografía y su relación con las artes, pero también sobre su naturaleza y las potencialidades de sus usos como nuevo medio de comunicación, como símbolo de progreso para la sociedad y el conocimiento, conformando un conjunto de «intuiciones fundacionales» de lo que se ha llamado «teoría popular» de la fotografía (Costello, 2018: 9). Incluso antes de su invención, ciertos personajes ya especularon sobre una «idea preexistente» de fotografía (Brunet, 2000: 33) a través de la creación literaria -Thiphaigne de la Roche-, la conjetura científica -Thomas Wedgood-o el deseo ardiente de lograr su invento -Louis Daguerre- (Batchen, 2004).

En 1927, en el agitado contexto europeo de las vanguardias artísticas del periodo de entreguerras Franz Roh, en su polifacética condición de crítico y fotógrafo -por entonces más insólita y abrumadora que en la actualidad-, expresaba con acierto la tensión entre la práctica artística y la reflexión teórica mediante la figura de "la doble cuerda» para referirse, no sin inquietud, a la "osadía» de ciertos artistas de conciliar -pero no «igualar»- «esferas de acción tan opuestas y hasta hostiles entre sí» como «la potencia afirmativa y creadora del artista» y "la de teorizar y fundamentar» propia del crítico. Era la manera de responder a la «falta de ejercicio intelectual de las pasadas generaciones» de artistas (Roh, 1997: 21-22). Unos años más tarde, en el heterogéneo panorama artístico de los setenta, regado por el arte conceptual, el también fotógrafo y crítico Bill Jay escribía que

El fotógrafo puede usar los procesos del pensamiento racional preparando su mente para tener destellos de percepción y claridad de visión. Esto implica una disposición a leer, escribir, pensar, estudiar (...) El 
buen fotógrafo es siempre un intelectual, opuesto a un animador que simplemente actúa haciendo trucos estilísticos para su público (Jay, 1979: 89)

Los fotógrafos, como los artistas, estaban requeridos a pensar su propia producción y, a la postre, la fotografía como medio creativo.

Sin embargo, estos intentos adolecían de una estructura conceptual asentada y, sobre todo, no asumían expresamente su quehacer como un conocimiento específico: era una reflexión que no se reconocía a sí misma como saber. Pero que no existiera una consciencia teórica por parte de los fotógrafos -tampoco de los críticos, aunque sin duda creciente con el avance del proceso de su institucionalización- no excluye que las fotografías conllevaran para sus autores "la búsqueda de una posición» (Flusser, 1994: 114) si no teórica en un sentido fuerte, sí al menos de experimentación estética, intención social o de un cierto grado de actitud crítica (Wells, 2007: 345). Ni tampoco excluye que sus textos o manifiestos constituyan una manera de "pensar» e «imaginar» la fotografía por el «medio corolario del lenguaje escrito» (Trachtenberg, 1991: 1). Por tanto, las reflexiones e ideas acerca de la fotografía tienen, y han tenido, un alcance más allá de "las demandas pragmáticas de la práctica misma» (Smith y Lefley, 2015: 153) y, como más adelante veremos, dicho alcance dependerá de la orientación teórica que se adopte cuando se haga explícita -a finales de los años setenta- la exigencia epistemológica de constituir un marco disciplinar para la fotografía.

La reciprocidad entre teoría y práctica es un hecho incontestable en los dominios de lo fotográfico. Podemos afirmar con David Bate que no existe un «modo no teórico» de entender la fotografía pues «toda práctica presupone una teoría» (Bate, 2016: 11). Desde la perspectiva de la representación visual, así como de las experiencias de producción y percepción que generan, las fotografías pueden formar y transformar teorías tanto como las teorías ayudan a explicar el significado o la función de las fotografías. Si la práctica es un campo para la teoría, esta lo es también para la práctica. Ya fuese cuando las aspiraciones artísticas dominaban la práctica fotográfica en su primera época, en el agitado periodo de las vanguardias históricas o cuando a finales del siglo XX la fotografía invadió los dominios del arte, los escritos de artistas, fotógrafos y críticos sobre la fotografía constituyen una práctica discursiva por propio derecho que daría lugar a lo que Alan Trachtenberg (1980: vii) primero y Christopher Phillips (1989: xii) después han Ilamado una «historia intelectual» de la fotografía, en cuyos registros se situaría la genealogía de la teoría de la fotografía.

\section{EL GIRO CRÍTICO EN EL ARTE Y LA FOTOGRAFÍA AR- TÍSTICA A PARTIR DE LOS AÑOS SESENTA DEL SIGLO $X X$ : CONDICIONES DE EMERGENCIA DE LA TEORÍA DE LA FOTOGRAFÍA}

Nuestra tesis es que en las condiciones de emergencia de la teoría de la fotografía como disciplina se concitaron el giro crítico del arte conceptual en los años sesenta, la subsiguiente aparición de las prácticas artísticas posmodernas a finales de los setenta y, en paralelo a ambos momentos entrelazados de convergencia de arte y fotografía, la institucionalización de la fotografía artística con su incorporación al museo y la aparición de un pujante mercado fotográfico. La necesidad de la teoría de la fotografía se perfiló mientras el museo y el mercado respaldaban un ideario estético propio de la fotografía artística, a la vez que ciertos planteamientos artísticos trazaban un programa crítico sobre dicho ideario y su efecto legitimador. De este modo, al mismo tiempo que museos, coleccionistas, historiadores y críticos ponían su atención en la fotografía como medio específico, apoyados en el reconocimiento de una tradición de maestros y obras maestras de la fotografía (Newhall, 2006), la imagen fotográfica entraba en la práctica artística como «objeto teórico", es decir, como dispositivo de exploración crítica del campo del arte (Krauss, 2002: 14-17). Esta intersección tensionó el horizonte artístico de la segunda mitad de la década de los setenta entre «la fotografía como arte» -la fotografía como objeto artístico por sí mismo- y «el arte como fotografía» -el arte cuyo programa adopta críticamente la fotografía como medio- (Neusüss, 1979), abriendo un fértil debate intelectual entre los agentes del mundo artístico.

Los años sesenta, por un lado, asistieron a la musealización y a la mercantilización de la fotografía que culminaban un proceso de legitimación artística que había comenzado con la creación del Departamento de Fotografía del MoMA en 1940 (https://www.moma. org/documents/moma_catalogue_2089_300144985. pdf). La fotografía se vio asimilada así al canon de la modernidad estética fijado por Clement Greenberg (2006) como medio cuya especificidad la habilitaba para desarrollar un programa propio de autorrevisón crítica de su lenguaje, tal como quedó manifiesto en el hito expositivo El ojo del fotógrafo (2010), comisariado por John Szarkowski en 1964. Por el otro, estos años fueron testigo de la germinación de toda una variedad de nuevos comportamientos conceptuales que priorizaban la idea sobre la factura artística, el 
placer intelectual sobre el visual y el proceso sobre la materialidad de la obra. Las condiciones de posibilidad del arte como práctica se vieron transformadas por completo, propiciando que la teoría deviniera en una forma de práctica (Smith y Lefley, 2015: 159). En esta trama artística, la fotografía comienza a adquirir un nuevo protagonismo, auspiciada por la quiebra de la jerarquía institucionalizada de los medios y sus valores estéticos asociados. Los artistas conceptuales incorporan la fotografía para documentar sus acciones, performances e instalaciones, conformándose como parte de la obra, cuando no en la obra misma. A la función de registro indicial se le adhería además un "gesto performativo» del acto fotográfico de carácter deíctico (Green y Lowry, 2007: 61), de conexión con el mundo real y la vida cotidiana en sus facetas social y política (Bate, 2016: 177-178 y Chevrier y Lingwood, 2004). No interesaba la fotografía por sus cualidades estéticas sino por su «indiferencia» derivada de un sistema de producción de imágenes mecánico, reproducible y carente de aura (Wall, 2003). Los artistas conceptuales adoptaron el medio fotográfico con «promiscuidad» -frente a la "fidelidad» de los profesionales-, desatendiendo deliberadamente sus propiedades plástico-formales (Kent, 1979: 192).

A finales de la década de los setenta y comienzos de los ochenta, la producción artística heredera de la poética conceptual trajo consigo un creciente uso de la fotografía como eje de procesos de hibridación: con las prácticas posmodernas la fotografía remataba su convergencia con el arte a costa de su especificidad como medio (Crimp, 2000 y 2004; Chevrier y Lingwood, 2004). Con la posmodernidad el discurso de la fotografía ya no será el estético sino el de un proyecto de deconstrucción -no solo visual sino también intelectual- por el que el arte, de acuerdo con las palabras de Rosalind Krauss, se distancia y separa de sí mismo, con la imagen fotográfica jugando el papel de metalenguaje, para poner al descubierto los mitos del arte como lenguaje (Krauss, 2002). Mitos que, en última instancia, eran los mismos que había adoptado la fotografía artística, de manera que esta tampoco salió indemne del proceso.

En efecto, la herencia fotoconceptual fue compleja y contradictoria, y conforme avanzaba el programa crítico de instrumentalización de la imagen fotográfica se producía paradójicamente, como observa Jeff Wall, un efecto catalizador de afianzamiento sobre el ideal greenbergiano de autonomía estética que la fotografía artística llevaba a cabo como medio institucionalizado (Wall, 2003: 213). En este sentido, John Szarkowski, en la exposición Mirrors and Windows. American Photography since 1960 presentada en el MoMA en 1978, ofrecía una visión del fotoconceptualismo entrelazado con el modernismo estético, ambos concebidos como manifestaciones de un mismo impulso fotográfico que oscila entre el «espejo» que refleja la mirada del artista y la «ventana» a través de la cual conocer el mundo. Se incluyeron obras de Robert Heinecken, Les Krims, Andy Warhol, Robert Rauschenberg, Ed Ruscha y Sol Lewit. Dirigiendo el argumento de los autores y sus etiquetas hacia las obras fotográficas, Szarkowski afinaba que «como quiera que se llame a tales obras, han sido muy importantes para aquellos que se llaman a sí mismos fotógrafos, pintores, grabadores o artistas conceptuales, y para aquellos que encuentran todas esas etiquetas restrictivas». El tema de la exposición no eran "los fotógrafos, sino la fotografía», lo esencial era considerar «el carácter y la influencia del trabajo» antes que las convicciones de su autor (Szarkowski, 1978: 16)². Un intento de fagocitación artística a contrapelo de la realidad histórica que, desde nuestro punto de vista, daría la pista de un clima que propiciaba la construcción de un marco teórico compartido por el conjunto de las prácticas fotográficas.

Por otra parte, esta posibilidad teórica no sería por completo comprensible si junto a la deriva conceptual y deconstructiva no se tuviera en cuenta que paralelamente, y de forma complementaria, en la década de los setenta surgió un tipo de imagen en la que el fotógrafo dejaba de estar a la espera de que algo sucediera para su registro y pasaba a "fabricar» ante la cámara de "modo dirigido» la escena de aquello que quería retratar (Van Deren Coke, 1979; Coleman, 2004). En estos trabajos se desafiaba la evidencia convencionalmente otorgada a la fotografía mediante la creación de "falsos documentos» fotográficos. Frente a la concepción de la fotografía como testigo ocular expectante, surgió esta otra propuesta que optaba por la puesta en escena como medio de expresión artística. De la observación directa del mundo a través de la cámara se pasó a un planteamiento crítico que revisaba el acto de observación fotográfica, evidenciando los mecanismos de la construcción de la imagen y su significado a través de diferentes estrategias de escenificación (Hoy, 1987). Como se encargó de subrayar Alan D. Coleman (2004: 138), los antecedentes históricos de este paradigma fotográfico se podían rastrear desde las modulaciones pictorialistas de la fotografía de finales siglo XIX y comienzos del XX. Pero la irrupción de la fotografía escenificada en las prácticas artísticas de los años setenta y su definitivo desarrollo en los posmodernos ochenta, se había 
gestado una década antes cuando en los años sesenta tuvo lugar una ruptura de las lindes entre disciplinas artísticas que propiciaba su contaminación y mixtura. De un lado, tal como ya se ha señalado, bajo estímulo del arte conceptual surgió la documentación fotográfica del arte de acción -performance, happenings y body art-concebida como huella del acontecimiento preparado por el artista pero también como vehículo del concepto encerrado en la acción registrada por la cámara. Del otro, como deriva de la estética del pop art que, inspirada en la iconografía de la de cultura de masas, reforzaba la idea de que todo, incluidas las obras de arte, forma parte del gran simulacro de la representación mediática.

\section{LA INVENCIÓN DE LA TEORÍA DE LA FOTOGRAFÍA: ASPECTOS EPISTEMOLÓGICOS Y SOCIALES}

En este caldo de cultivo irrumpe la necesidad de hacer explícito un pensamiento reflexivo en torno a la fotografía, dando lugar, en expresión de Smith y Lefley, a la «invención» de la teoría de la fotografía (Bate, 2016: 163). En una entrevista de Angelo Schwartz a Roland Barthes, realizada en 1977, el crítico italiano preguntaba por qué no existía una teoría de la fotografía al contrario de lo que sucede con el cine, un medio que a pesar de contar con una trayectoria histórica más corta poseía, en cambio, un fundamento teórico más amplio y sistemático. En su respuesta el semiólogo francés apuntaba que la causa estaba en que el verdadero desarrollo del cine fue como ficción y no como práctica al servicio del registro de la realidad como hizo la fotografía (Gunthert, 2016: 1). El cambio radical producido en la fotografía en los años sesenta y setenta vendría a apoyar el argumento de Barthes en la medida en que se cuestionó su estatuto documental abriendo para la fotografía nuevas perspectivas de carácter narrativo mediante la adopción de recursos como el montaje, la hibridación medial y la escenificación.

La demanda de un discurso teórico sobre la fotografía y el reconocimiento de su identidad epistemológica se explicitaron por primera vez en 1978, en el número 5 de la revista October, dedicado monográficamente a la fotografía a cargo de las críticas de arte Rosalind Krauss y Annette Michelson (2004); a continuación en 1980 lo hizo el profesor Alan Trachtenberg en Classic Essays on Photography y con más concreción Victor Burgin en Thinking Photography en $1982^{3}$. Todos ellos compartían un mismo diagnóstico: el vacío de la teoría de la fotografía como tal porque la fotografía había estado relegada a «un limbo cultural» del que había que redimirla para apuntalar la «iniciativa embrionaria de una teoría de la fotografía» (Krauss y Michelson, 2004: 145-146); por «carecer de una tradición crítica, de escritura seria» capaz de generar una «inteligencia colectiva», esto es, una comunidad intelectual de producción, discusión e intercambio de ideas relacionadas con el medio fotográfico (Trachtenberg, 1980: viii); o bien porque simple y llanamente «la teoría de la fotografía todavía no existe», pues no era una realidad sino un objetivo "hacia» el que dirigir el trabajo intelectual (Burgin, 1982: 1).

En un sentido amplio, podemos caracterizar una teoría como un conjunto de supuestos, mínimamente estructurado y coherente, que sirve para explicar y comprender un determinado fenómeno (Casetti, 1994: 11). Cada una de las iniciativas editoriales ofrecía una selección de textos, realizada según distintos criterios intelectuales, que servían como contribuciones para el diseño conceptual y metodológico de una teoría de la fotografía, más o menos explícita y delimitada, casi a modo de una definición ostensiva de teoría de la fotografía. Sin duda es Victor Burgin quien mejor ubica la nueva disciplina al definirla como un sistema organizado de ideas y conocimientos objetivos que ha de construir argumentos fundamentados racionalmente y basados en hechos, deslindándola así de otras cercanas como la crítica y la historia de la fotografía -Trachtenberg precisa igualmente esta distinción pero de una forma más sucinta-, ambas lastradas por una misma ideología estética (Burgin, 1982: 3-4). En el fondo, las tres propuestas comparten el carácter interdisciplinar de un sistema teórico que ha de hacerse cargo de un objeto tan heterogéneo como la fotografía, aunque es Burgin (1982: 12) el único que lo anota de manera expresa ${ }^{4}$. Si desde la revista October, al igual que Trachtenberg, se aborda fundamentalmente la fotografía como obra de arte, Burgin en cambio enfoca la fotografía más que como signo estético como una "práctica de significación» que además de la producción incluye los momentos de distribución y consumo de las fotografías como objeto de análisis.

Krauss y Michelson proponían una suerte de arqueología crítica del medio fotográfico que desvelara una tradición y una estética. En su selección de textos se combinaba la relectura histórica -la misma Krauss, Hollis Frampton y Jean Claire-, el análisis postestructuralista -Craig Owens y Douglas Crimp- y la reflexión de corte filosófico -Hubert Damisch y Thierry De Duve-. Trachtenberg ofrecía una recopilación histórica que, sin pretensiones de estricta continuidad, dibu- 
jaba una cartografía textual de corte más académico en la que a las reflexiones sobre la relación con el arte o la especificidad del medio de los fotógrafos -desde pioneros como Niépce a abanderados de la modernidad como Moholy-Nagy y Walker Evans-, se sumaban escritos de teóricos culturales como Walter Benjamin, Roland Barthes o John Berger para quienes las preocupaciones estéticas no estaban desligadas de las culturales y políticas ${ }^{5}$. Por su parte, Victor Burgin, en su condición de ensayista y artista conceptual, orquestaba un complejo marco teórico deudor del materialismo marxista, el psicoanálisis y la semiótica que debía responder a su idea de la fotografía como una «práctica de significación». Los textos, en los que incluían varías aportaciones propias, giraban en torno a los medios de producción artística -Walter Benjamin-, la relectura de la estética fotográfica de las vanguardias históricas -Simon Watney-, los códigos que articulan la imagen -Umberto Eco-, el análisis ideológico de la representación fotográfica combinando la semiótica y la historia social -John Tagg y Allan Sekula- o a la participación activa de los procesos mentales del espectador en términos psicoanalíticos -Victor Burgin-.

España no fue ajena a este interés teórico surgido a nivel internacional y, en 1984, Joan Fontcuberta publica Estética fotográfica, una selección de textos de fotógrafos que abarcaba desde la invención del medio hasta las vanguardias y la posguerra mundial. Se trata de la primera edición de escritos históricos sobre fotografía realizada en el ámbito hispanohablante y presentada como corpus teórico de una estética de la fotografía. En línea con lo argumentado por los editores anglosajones, esta iniciativa evidenciaba el desinterés por la fotografía ostentado tradicionalmente por la clase intelectual. Fue un proyecto aislado pero motivado por el contexto fotográfico español en transformación desde la precedente década de los setenta. Esta publicación constituyó un hito fundamental en el incipiente apuntalamiento artístico y teórico de la fotografía en nuestro país ${ }^{6}$ como catalizador del proceso de «normalización» del medio fotográfico que empezaba a tener lugar a través de eventos y exposiciones, de la apertura puntual de galerías especializadas y de la aparición de un incipiente mercado fotográfico. Todo ello al amparo del «entusiasmo» que, con la consolidación del sistema democrático y el desarrollo de políticas culturales públicas, envolvió al arte español de la década de los ochenta (Brea, 1989). Ciertamente, no podemos abundar ahora en el desarrollo de la teoría de la fotografía en España en la segunda mitad del siglo XX pero sí incidir en el activo papel seguido por Fontcuberta en este dominio-siempre atento a los discursos en torno al medio surgidos en el ámbito internacional- con la posterior publicación en 1997 de $E$ l beso de Judas, donde reflexionaba críticamente sobre los atributos de verdad y objetividad conferidos a la imagen fotográfica en virtud de su condición de registro de la realidad. Reflexiones que arropaban intelectualmente los planteamientos estéticos de sus proyectos artísticos Herbarium (1984) y Fauna (1989) en los que desafiaba los límites entre realidad y ficción, poniendo a prueba las convicciones y los esquemas cognitivos del espectador.

Por último, además de la dimensión epistemológica cabe considerar la dimensión social jugada por la teoría de la fotografía en aquellos momentos de emergencia, en particular a través de los modos con los que "se asoma a la escena colectiva» (Casetti, 1994: 13). En este sentido, Rosalind Krauss y Annette Michelson, conocedoras de las paradojas y contradicciones que acechan a la práctica fotográfica, reflexionan críticamente sobre la complicidad de teóricos y estudiosos de la fotografía con el establecimiento del estatus de la fotografía como mercancía dentro del sector del comercio artístico. Nociones como valor, aura, autenticidad o estructura formal fueron adaptadas por la erudición histórica y crítica a la fotografía para eximirla de los lastres de su automatismo y utilidad. Al fotógrafo se le reconoce como artista y a la imagen fotográfica como portadora de las «marcas de un acto de creatividad intelectual o subjetivo». Estas fueron las premisas que posibilitaron y sustentaron la aparición del comercio de la fotografía artística, a pesar del desdén tradicionalmente exhibido hacia el mercado por la erudición y la educación artísticas (Krauss y Michelson, 2004: 146-147)7.

Victor Burgin, por su parte, apunta específicamente el hecho de que la teoría de la fotografía pueda ser enseñada y servir como elemento de «intervención» en el campo de la educación artística. En su rol de artista conceptual y como profesor en activo del Polytechnic of Central London durante la preparación y publicación del libro Thinking Photography, el tema educativo es una cuestión central. En los años sesenta y setenta las prácticas conceptuales tuvieron un importante impacto en el sistema educativo del arte, especialmente en el Reino Unido. Escuelas de arte y universidades se convirtieron en puntos de agitación artística y fotográfica para la transformación del modelo tradicional de educación artística (Smith y Lefley, 2015: 160-163). Burgin (1982: 2-3) otorga a la teoría de la fotografía una función heurística crucial para armar el espíritu crítico y el pensamiento independiente 
de los futuros fotógrafos y artistas. Un objetivo que Alan Trachtenberg (1980: viii) comparte al ver en el pensamiento teórico sobre la fotografía un medio para despertar y avanzar en un conocimiento crítico latente en estudiantes y fotógrafos.

En un contexto social y cultural completamente distinto -sin expectativas para la formación fotográfica en el ámbito educativo español de aquellos años-, Joan Fontcuberta (1984: 7-9) antepone para la teoría de la fotografía un objetivo pragmático frente a los de carácter académico: incentivar en los fotógrafos la necesidad de llevar a cabo una reflexión sobre su obra, de ser capaces de comprender sus intenciones estéticas y de valorar críticamente sus resultados, siguiendo la pauta de lo reflejado en la mayoría de los escritos seleccionados en su libro sobre estética fotográfica. El ejercicio teórico de los propios autores se convertía en el medio de legitimación social y cultural de la fotografía, sin duda espoleado por la ausencia en nuestro país de una crítica especializada y de instituciones encargadas de ejercer dicha labor.

\section{CONCLUSIÓN ABIERTA}

Los años finales de los setenta y los primeros ochenta asistieron al surgimiento de la fotografía como objeto teórico y a la configuración de la teoría de la fotografía como una disciplina que debía definir su identidad epistemológica frente a la historia y la crítica fotográficas y reconocerse como parte $-y$ en cierto modo, como culminación y comienzo- de la historia intelectual de la fotografía, como parte inseparable de la historia integral del medio. La legitimación de la fotografía artística con su entrada en el museo, el giro crítico provocado en el arte por las prácticas conceptuales con su separación del canon moderno y la instrumentalización de la imagen fotográfica colocaron a ese medio en el centro de la reflexión teórica y crítica.

La propuesta de un marco teórico para la fotografía planteado por Krauss y Michelson, Trachtenberg y Burgin se sustentaba en un débil esbozo de teoría de la fotografía, una realidad todavía por desarrollar, cercada por el desafío de abordar un objeto de estudio heterogéneo con recursos metodológicos diversos, evidenciando la dificultad de una teoría unificada de la fotografía, ya fuese de carácter ontológico, estético o sociológico.

Los siguientes años en la década de los ochenta fueron muy prolíficos en producción teórica a ambos lados del Atlántico. En el continente europeo Henri Van Lier (1983), Philippe Dubois (1986) y Jean-Marie Schaeffer (1990) elaboraron, desde distintas posiciones intelectuales, estudios sobre la naturaleza indicial -como huella de luz- de la fotografía en el marco de un discurso destinado a clarificar el estatus ontológico de la fotografía, retomando el hilo argumental presente en Bazin (2001), Krauss (1996) y Barthes (1990). En 1983 el filósofo y comunicólogo Vilém Flusser publica Hacia una filosofía de la fotografía (2001), intempestivo y heterodoxo ensayo sobre la fotografía como imagen técnica y sus implicaciones con el conocimiento y la libertad humanas. En el Reino Unido y en Estados Unidos tenía lugar un cambio de perspectiva sobre el medio donde ya no interesa qué es la fotografía sino qué hace la fotografía, y donde se abandona la cuestión esencialista sobre la identidad intrínseca del medio por el análisis histórico y social del papel cultural e ideológico que las imágenes fotográficas juegan dentro de unas determinadas condiciones y circunstancias (Trachtenberg, 1991: 6). Trabajos de referencia como el de John Tagg (2005) o como los recopilados en las ediciones de Richard Bolton (1992), Carol Squiers (1990) y Daniel P. Younger $(1991)^{8}$ muestran esa deriva teórica que enlaza con una actitud escéptica hacia la herencia de una estética fotográfica, el interés por los procesos sociales y culturales afectados por la fotografía y la apertura a un pluralismo de lenguajes críticos inspirados en los análisis foucaultianos, en el marxismo benjaminiano o en la interpretación cultural barthesiana, avanzado así un paso adelante en la línea abierta por las iniciativas de Trachtenberg, Burgin, Krauss y Michelson.

\section{NOTAS}

1. Para un sintético recorrido histórico a través de las manifestaciones de la teoría de la fotografía véase Kriebel (2007) y Mira (2009)

2. Es interesante recordar que unos años después, en los inicios del debate posmoderno sobre la fotografía, Andy Grundberg (1990: 14-16) precisaba cómo estos artistas conceptuales sin ninguna «lealtad» a la tradición estéti- ca de la fotografía ganaron en su momento más atención que los fotógrafos clásicos. A la vez sugería que las semillas de la actitud posmoderna había que encontrarlas en la obra de Walker Evans, Robert Frank y Lee Friedlander con su visión de la cultura popular y la sociedad norteamericanas del siglo XX. Para Grundberg las prácticas artísticas posmodernas -en contra de la opinión de críticos como Douglas Crimp pero inspirado en teóricos como Jacques Derrida- surgieron de un desarrollo crítico del modernismo.

3. De modo simultáneo tuvieron lugar otras notables recopilaciones de textos de fotógrafos como la de Beaumont Newhall (1980), que seguía la estela de los trabajos de Jonathan Green (1973) y Nathan Lyons (1966), o la 
vasta compilación realizada por Vicky Goldberg (1981) en la que el listado de fotógrafos se salpicaba con nombres de pensadores y filósofos. A diferencia de las tres iniciativas editoriales en las que nos hemos centrado, ni Newhall ni Goldberg -tampoco Green o Lyons antes- plantearon explícitamente ninguna cuestión relativa a la necesidad de dar forma a una teoría de la fotografía, pero sus propuestas fueron una respuesta al interés intelectual que el medio fotográfico comenzaba a despertar en aquellos momentos.

4. En este planteamiento se puede ver un eco del enfoque interdisciplinar -semiótica, teoría feminista, antropología, sociología, crítica del arte y estudios sobre cine- que llevaron a cabo los Estudios Culturales en su análisis crítico de la subordinación ideológica de las prácticas culturales, una tendencia que en aquellos años se extendió por las universidades británicas y que, en opinión de Burgin (1982: 1), constituirá el background para posicionar los artículos del libro.

\section{REFERENCIAS}

Barthes, Roland (1990). La cámara lúcida: nota sobre la fotografía. Barcelona: Paidós.

Barthes, Roland (1996). Lo obvio y lo obtuso. Imágenes, gestos, voces. Barcelona: Paidós.

Batchen, Geoffrey (2004). Arder en deseos: la concepción de la fotografía. Barcelona: Gustavo Gili.

Batchen, Geoffrey (ed.) (2009). Photography Degree Zero. Reflections on Roland Barthes's Camera Lucida. Cambridge, Mass.: MIT Press.

Bate, David (2016). Photography. New York/London: Bloomsbury.

Bazin, André (2001). ¿Qué es el cine? Madrid: Rialp.

Bolton, Richard (ed.) (1992). The Contest of Meaning. Critical Histories of Photography. Cambridge, Mass.: MIT Press.

Bourdieu, Pierre (2003). Un arte medio: ensayo sobre los usos sociales de la fotografía. Barcelona: Gustavo Gili.

Brea, José Luis (1989). Before and After the Enthusiasm / Antes y después del entusiasmo. Amsterdam: Contemporary Art Foundation.
5. Al final del libro se incluye un breve apéndice con referencias de una serie lecturas adicionales que venían a completar y a actualizar su selección textual. La lista no es extensa pero sí diversa. Se relacionan artículos precursores del pensamiento teórico sobre la fotografía junto a otros de inspiración semiótica - psicoanalítica, ensayos culturales, además de escritos de algunos críticos y referentes clásicos de la historia de la fotografía. Asimismo aparece citado el número especial sobre fotografía de la revista October.

6. En 2003 aparece la edición revisada de Estética fotográfica que incluye textos de Salvador Dalí y Pere Català-Pic, poniendo de manifiesto la existencia de un pensamiento de origen español en torno a la fotografía a la espera de ser recuperado e investigado. En este sentido, es importante recordar que en 1984 también tuvo lugar la exposición Idas y caos: aspectos de las vanguardias fotográficas en España 1920-1945, comisariada por el mismo Fontcuberta. Sin precedentes en la investigación

Brunet, François (2000). La naissance de l'idée de photographie. Paris: Presses Universitaires de France.

Burgin, Victor (ed.) (1982). Thinking Photography. London: Macmillan Education. https://doi.org/10.1007/978-1-34916716-6

Casetti, Francesco (1994). Teorías del cine, 1945-1990. Madrid: Cátedra.

Chevrier, Jean François y Lingwood, James (2004). Otra objetividad. En: Jorge Ribalta (ed.). Efecto real. Debates posmodernos sobre fotografía. Barcelona: Gustavo Gili, pp. 240-277.

Coleman, Allan Douglas (2004). El método dirigido. Notas para una definición. En: Jorge Ribalta (ed.). Efecto real. Debates posmodernos sobre fotografía. Barcelona: Gustavo Gili, pp. 129-144.

Costello, Diarmuid (2018). On photography. A Philosophical Inquiry. London/ New York: Routledge. https://doi. org/10.4324/9781315266688

Crimp, Douglas (2000). Imágenes. En: Anna Maria Guasch (coord.). Los manifiestos del arte posmoderno: textos de exposiciones 1980-1995. Madrid: Akal, pp. 87-95. historiográfica de la fotografía española ni en la programación expositiva de aquellos años, esta iniciativa rescató los nombres y la producción fotográfica de una serie artistas del periodo de vanguardia de los años veinte y treinta sumidos en el olvido. La restitución de una historia de la fotografía ignorada y el reconocimiento teórico -en términos estéticos- del medio acontecieron en España simultánea, y oportunamente, en la década de los ochenta de la mano de Joan Fontcuberta en su papel de teórico e historiador de la fotografía.

7. Como lo fueron también para su entrada en el MoMA, especialmente de la mano de Newhall y Szarkowaki, gracias a la inversión de la imagen fotográfica de reproductible en aurática (Phillips, 2003).

8. En España siguieron la estela de estas publicaciones los compendios de textos inéditos en castellano realizados por Gloria Picazo y Jorge Ribalta (2003) y por el propio Ribalta (2004).

Crimp, Douglas (2004). La actividad fotográfica de la posmodernidad. En: Jorge Ribalta (ed.). Efecto real. Debates posmodernos sobre fotografía. Barcelona: Gustavo Gili, pp. 150-162.

Dubois, Philippe (1986). El acto fotográfico. De la representación a la recepción. Barcelona: Paidós.

Dubois, Philippe (2016). De l'image-trace a l'image-fiction. Le mouvement des theories de la photrographie de 1980 à nos jours. Études photographiques, 34, pp. 1-15. Disponible en https:// journals.openedition.org/etudesphotographiques/3593 [Fecha de consulta: 4 diciembre 2019].

Elkins, James (ed.) (2007). Photography Theory. New York/London: Routledge.

Flusser, Vilém (1994). Los gestos: fenomenología y comunicación. Barcelona: Herder.

Flusser, Vilém (2001). Hacia una filosofía de la fotografía. Madrid: Síntesis.

Fontcuberta, Joan (1984). Idas y caos: aspectos de las vanguardias fotográficas en España 1920-1945. Madrid: Ministerio de Cultura.

Fontcuberta, Joan (ed.) (2003). Estética fotográfica. Barcelona: Gustavo Gili. 
Fontcuberta, Joan (2010). La cámara de Pandora. La fotografía después de la fotografía. Barcelona: Gustavo Gili.

Freund, Gisèle (2001). La fotografía como documento social. Barcelona: Gustavo Gili.

Fried, Michael (2008). Why Photography Matters as Art as never before. New Haven/London: Yale University Press.

Goldberg, Vicki (ed.) (1981). Photography in Print. Alburquerque: University of New Mexico Press.

Gómez-Cruz, Edgar (2012). De la cultura Kodak a la imagen en red. Una etnografía sobre fotografía digital. Barcelona: Editorial Universitat Oberta de Catalunya.

Green, Jonathan (ed.) (1973). Camera Work: A Critical Anthology. New York: Aperture.

Green, David y Lowry, Joanna (2007). De lo presencial a lo performativo: nueva revisión de la indicialidad fotográfica. En David Green y Joanna Lowry (eds.) ¿Qué ha sido de la fotografía? Barcelona: Gustavo Gili, pp. 49-64.

Greenberg, Clement (2006). La pintura moderna y otros ensayos. Madrid: Siruela.

Grundberg, Andy (1990). Crisis of the Real. Writings on Photography, 1974-1989. New York: Aperture.

Gunthert, André (2016). Une illusion essentielle. La photographie saisie par la théorie. Études photographiques, 34, pp. 1-15. Disponible en https://journals.openedition.org/etudesphotographiques/3592. [Fecha de consulta: 2 diciembre 2019].

Hoy, Anne H. (1987). Fabrications. Staged, Altered and Appropriated Photographs. New York: Abbeville Press.

Iglhaut, Stefan; Rotzer, Florian; Cassel, Alexis; Schneider, Nikolaus G. y Ameluxen, Hubertus V. (eds.) (1996). Photography after Photography: Memory and Representation in the Digital Age. Basel: GyB Arts International.

Jay, Bill (1979). Negative/Positive. A philosophy of Photography. Dubuque, lowa: Kendall/Hunt Publishing.

Kent, Sarah (1979). Photography: Social and Sensual. En: Neusüss, Floris M. (ed.). Fotografie als Kunst, Kunst als Fotografie. Köln: Dupont, pp. 186-203.

Krauss, Rosalind (2002). Lo fotográfico. Por una teoría de los desplazamientos. Barcelona: Gustavo Gili.
Krauss, Rosalind (1996). La originalidad de la vanguardia y otros mitos modernos. Madrid: Alianza.

Krauss, Rosalind y Michelson, Annette (2004). Fotografía: número especial. En Jorge Ribalta (ed.). Efecto real. Debates posmodernos sobre fotografía. Barcelona: Gustavo Gili, pp. 145-149.

Kriebel, Sabine T. (2007). Theories of Photography. A Short History. En: James Elkins (ed.). Photography Theory. New York/ London: Routledge, pp. 3-49.

Lister, Martin; Dovey, Jon; Giddings, Seth; Grant, lain y Kelly, Kieran (eds.) (2003). New media: A Critical Introduction. London: Routledge.

Lyons, Nathan (ed.) (1966). Photographers on Photography: A Critical Anthology. New Jersey: Prentice-Hall.

Martín Prada, Juan (2018). El ver y las imágenes en los tiempos de internet. Madrid: Akal.

Mira, Enric (2009). Notas sobre el desarrollo de la teoría de la fotografía en la segunda mitad del siglo XX. En Pedro Vicente (ed.). Instantáneas de la teoría de la fotografía. Tarragona: Arola Editors, pp. 39-58.

Mitchell, William J. (1992). The Reconfigured Eye: Visual Truth in the Post-Photographic Era. Cambridge, Mass.: MIT Press.

Neusüss, Floris M. (ed.) (1979). Fotografie als Kunst, Kunst als Fotografie. Köln: Dupont.

Newhall, Beaumont (ed.) (1980). Photography: Essays and Images. New York: MoMA.

Newhall, Beaumont (2006). Historia de la fotografía. Barcelona: Gustavo Gili.

Phillips, Christopher (ed.) (1989). Photography in the Modern Era. European Documents and Critical writings, 19131940. New York: Metropolitan Museum of Art/Aperture.

Phillips, Christopher (2003). El tribunal de la fotografía. En: Gloria Picazo y Jorge Ribalta (eds.). Indiferencia y singularidad. Barcelona: Gustavo Gili, pp. 53-96.

Picazo, Gloria y Ribalta, Jorge (eds.) (2003). Indiferencia y singularidad. Barcelona: Gustavo Gili.

Ribalta, Jorge (ed.) (2004). Efecto real. Debates posmodernos sobre fotografía. Barcelona: Gustavo Gili.
Roh, Franz (1997). Realismo mágico. Post expresionismo: problemas de la pintura europea más reciente. Madrid: Alianza.

Rubinstein, Daniel y Sluis, Katrina (2008). A life more photographic. Photographies, 1 (1), pp. 9-28. https://doi. org/10.1080/17540760701785842

Schaeffer, Jean Marie (1990) La imagen precaria. Del dispositivo fotográfico. Madrid: Cátedra.

Smith, Peter y Lefley, Carolyne (2015). Rethinking Photography. Histories, Theories and Education. New York/ London: Routledge. https://doi. org/10.4324/9781315722412

Sontag, Susan (2007). Sobre la fotografía. Barcelona: Alfaguara.

Squiers, Carol (ed.) (1990). The Critical Image. Essays on Contemporary Photography. Seattle: Bay Press.

Szarkowski, John. (1978). Mirrors and Windows. American Photography since 1960. New York: MoMA.

Szarkowski, John. (2010). El ojo del fotógrafo. Madrid: La Fábrica.

Tagg, John (2005). El peso de la representación. Ensayos sobre fotografías e historias. Barcelona: Gustavo Gili.

Trachtenberg, Alan (ed.) (1980). Classic Essays on Photography. New Haven, Conn.: Leete's Island Books.

Trachtenberg, Alan (1991). Introduction. En: Younger, D. (ed.). Multiple Views. Logan Grant Essays on Photography 1983-89, Alburquerque: University of New Mexico Press, pp. 1-14.

Van Deren Coke, Frank (1979). Fabricated to be Photographed. San Francisco: San Francisco Museum of Modern Art.

Van House, Nancy (2011). Personal photography, digital technologies and the uses of the visual. Visual Studies, 25 (1) pp. 125-134. https://doi.org/10.1080/1 472586X.2011.571888

Van Lier, Henri (1983). Philosophie de la photographie. París: Les Cahiers de la Photographie.

Wall, Jeff (2003). Señales de indiferencia: aspectos de la fotografía en el arte conceptual o como arte conceptual. En: Gloria Picazo y Jorge Ribalta (eds.). Indiferencia y singularidad. Barcelona: Gustavo Gili, pp. 213-249. 
Wells, Liz (ed.) (2004). Photography: A Critical Introduction. London/New York: Routledge.
Wells, Liz (2007). Navigating theory now. En: James Elkins (ed.). Photography Theory. New York/London: Routledge, pp. 342-346.
Younger, Dan (ed.) (1991). Multiple Views. Logan Grant Essays on Photography 1983-89. Alburquerque: University of New Mexico Press. 